\title{
Gut Microbiota and Celiac Disease: Why Eat Gluten-Free if you are not Celiac?
}

\author{
Antonia Sinesi ${ }^{1 *}$, Martina Salvatorina Murgia ${ }^{2}$ and Cinzia Casu $^{3}$ \\ ${ }^{1}$ RDH Freelancer Canosa di Puglia, Italy \\ ${ }^{2}$ DDS Private Dental Practice, Oral Biotechnology Laboratory, Department of Surgical Science, University of Cagliari, Italy \\ ${ }^{2,3}$ DDS Private Dental Practice, Italy
}

Submission: November 12, 2020; Published: December 10, 2020

*Corresponding author: Antonia Sinesi, RDH Freelancer Canosa di Puglia, Italy

\begin{abstract}
Celiac disease (CD) is an immune-mediated enteropathy correlated to the gluten ingestion in genetically predisposed subjects. The current and only therapy is a Gluten Free Diet (GFD). In recent years, new therapies and complementary strategies are being studied, including the modulation of the intestinal microbiome. The gut microbiota is involved in the onset and perpetuation of intestinal inflammation of various chronic bowel diseases, including CD. Intestinal dysbiosis has been reported in not treated or treated (with the GFD) celiac individuals, compared to healthy ones. Numerous studies have identified different bacterial clusters associated with CD. However, it's still unclear whether gut dysbiosis is the cause or effect of $C D$.
\end{abstract}

Keywords: Celiac disease; Gluten free diet; Probiotic; Gut Microbiota; Dysbiosis; Bifidobacterium; Lactobacillus

Abbreviations: CD: Celiac Disease; GFD: Gluten Free Diet; GM: Gut Microbiota

\section{Introduction}

Celiac disease (CD) is an immune-mediated enteropathy triggered by the ingestion of gluten, in genetically predisposed individuals (positive for HLA DQ2 / DQ8 haplotype) [1]. Globally, the prevalence of CD has increased considerably, in North America it increased in tandem with inflammatory bowel diseases [2]. In recent decades, population based studies have confirmed that CD was also common in non-European countries with a predominantly Caucasian population, such as in the United States [3], Australia [4] and some Latin American countries including Peru, Argentina and Brazil [5]. Studies carried out in the Middle East and Southeast Asia [6], show a similar prevalence [7]. It's important to specify that other elements are involved in the CD etiopathogenesis, such as the environmental factors. For this reason, only $30 \%$ of genetically predisposed subjects will develop CD. Globally, there is a prevalence of $1-2 \%$ [1] while in Italy a slightly lower but still significant prevalence is observed. For this reason, in 2001 CD has been added in the list of "social" diseases. A recent study shows an estimated Italian prevalence of $1.58 \%$, significantly higher than in previous years [8]. In fact, around 10,000 new cases are diagnosed every year. Furthermore, a very interesting data is observed: 4 out of 6 patients are not aware that are celiac. CD typically has symptoms mainly linked to gut malabsorption such as nausea, vomiting, diarrhea, steatorrhea and constipation [9]. In recent years, there has been a change in the CD symptoms, in fact the "non-specific" forms are more frequent. The latter have very heterogeneous symptoms, defined as "extraintestinal" characterized by: weight loss [10], asthenia, chronic fatigue [11], headache [12], inappetence, short stature [13], delayed puberty [14], osteoporosis [15], infertility and abortion [16], asthma, dermatitis herpetiformis and others [17]. Among the extraintestinal symptoms we also find oral manifestations, such as recurrent aphthous stomatitis, enamel defects, glossitis and cheilitis [18-20]. The classic CD form has a typical symptomatology that doesn't pose diagnostic problems and allows a timely implementation of a "gluten free" diet (GFD), which is the only therapy that causes disease regress and avoids the onset of possible complications [21]. Conversely, the undiagnosed forms can progress and present various associated pathologies such as T-cell lymphoma [22], aplastic anemia [23], encephalitis [24] and vasculopathies [25]. 
Therefore, it's evident that the focus of the disease is early diagnosis. In the child, one of the most complications are the growth slowing, so an early diagnosis is essential to allow the child to express all the height that he can genetically reach. Diagnosis must be made within $8 / 9$ years, because growth potential is lost beyond this age $[1,26]$. Thanks to recent epidemiological studies and contrary to the original paradigm, it is now established that CD can present at any age with a wide range of intestinal and extraintestinal symptoms. Its prevalence, as in many other autoimmune diseases often found together with CD, has increased over time, especially in geographic regions characterized by a Western lifestyle. Initially, it was hypothesized that this phenomenon was secondary to the time of the gluten introduction at weaning, although several prospective studies that have monitored the child from birth, have challenged this premise by showing that neither the delayed nor early introduction of gluten, modify the CD risk [27-29]. In recent years, attention has been focused on the correlation between intestinal microbiota and CD to verify if there is a link between these two aspects [30,31]. Particularly, Bacteroides, Escherichia coli, Enterobacteriaceae and Staphylococcus were significantly more abundant in CD patients than in controls with greater diversity of these species [32-35].

According to these studies, gluten and also intestinal infections promote dysbiosis. As for the pathogenesis, gluten consists of two protein classes: gluteline (called glutenins in wheat) and prolamines (called gliadins in wheat, hordes in barley, secaline in rye, avenins in oats). Indeed, it's not all gluten that is responsible for the CD pathogenesis but some of its epitopes (sequences of amino acids), such as the 33-MER [36]. The 33-MER sequence is the most important toxic epitope responsible for most of the pathological effects of gluten. 33-MER would be able to trigger a series of inflammatory factors responsible for a progressive flattening of the intestinal mucosa up to complete atrophy of the villi (decrease in the ratio between the height and the surface of the villus). Histopathological examination also shows: crypts hypertrophy, infiltration of inflammatory cells (plasma cells, lymphocytes, eosinophils and mast cells) in the context of lamina propria and an increase of immunoglobulins (IgA, IgG and IgM), thus causing malabsorption symptoms (Figure $1 \& 2$ ). In healthy subjects, 33 MER is further degraded by intestinal bacterial proteases. In the celiac patient, on the other hand, the following changes are found:

a) Decrease of Lactobacillus and Bifidobacterium species (this cluster is used as a marker of good systemic health).

b) Increase of Bacteroides and Escherichia coli.

c) Slight increase of Salmonella, Shigella, Klebsiella.

d) Qualitative depletion of the microflora, i.e., at the same microbial concentration, the microbiota is depleted: fewer species are present than those should normally be present. In fact, normally there is an imprinting in our microbiota in which there are 30-40 different species. This is bad because a decrease in biodiversity is always a negative factor in natural ecosystems $[37,38]$.

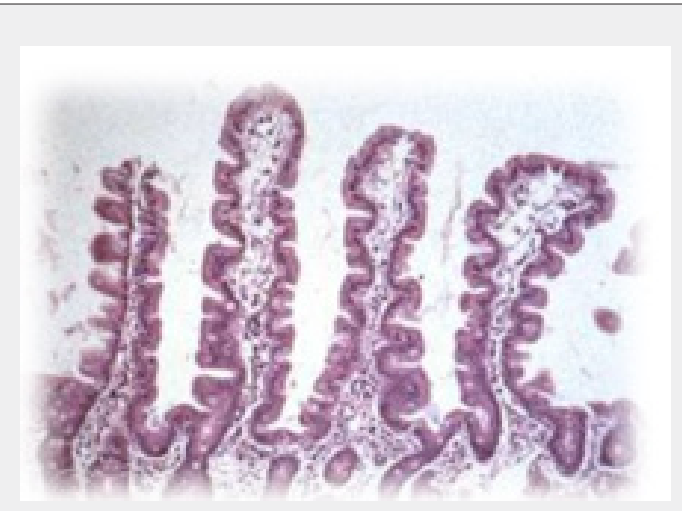

Figure 1: Histological section of intestinal villi in a healthy subject.

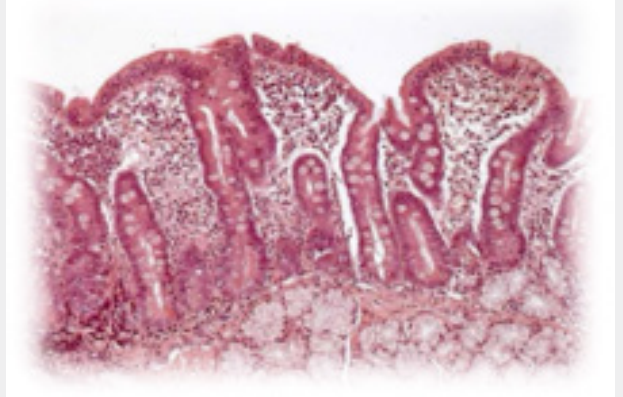

Figure 2: Histological section of intestinal villi in a subject affected by CD. 
These four signs are always present in celiac patients and are considered the four signs to be investigated (in addition to serological and histological tests) in order to understand if a subject is affected by $\mathrm{CD}$ or not. To support the important role of the microbiota and particularly the correlations between microbiota and CD, there is a very scientific evidence $[39,40]$. Wacklin et al. [38] were the first to introduce the gluten sensibility challenge. They highlighted that celiac patients, even if they follow a gluten free diet, will never have a complete re-establishment of the microbiota (even after years). Therefore, they will never have a condition of eubiosis, because the gut microbiota (GM) is altered. One of the hypotheses to contrast dysbiosis in celiac patients is the possibility of administering probiotics to mediate the restoration of the GM [41].

\section{What are the possible probiotics benefits? [42,43]}

i. Competition with pathogenic bacteria, particularly with gram-negative ones (which are increased in celiac patients).

ii. Modulation of the gut microflora, because probiotics promote Lactobacilli and Bifidobacterium, that are the useful bacterial component. iii. Effect on the mucosa functionality. There are many scientific evidence that probiotics promote a partial digestion of fibers, which lead to the production of short-chain fatty acids. The latter have an intestinal trophic function because they restore the mucosa barrier function.

Recent studies suggest that integration with Lactobacillus and Bifidobacterium spp may have a protective role because they decrease the 33-MER peptide immunogenicity. Furthermore, Lactobacillus and Bifidobacterium spp., have a complex proteolytic and peptidolytic system, thus they help the breakdown reaction of gluten and its peptides. Dysbiosis in the celiac patient is associated with alterations of the tight junctions with consequent greater intestinal permeability. In this way, there is a greater translocation of the gliadin peptides to the lamina propria $[44,45]$. De Simone formulation [46], a probiotic preparation composed mainly by Lactobacilli and Bifidobacteria, not only hydrolyzed the epitopes 62-75 and the peptide 33-MER derived from gliadin, but also improved the epithelial barrier function by stabilizing the tight junctions, through the modulation of zonulin [47]. In fact, zonulin appears to be partly responsible for the increased intestinal permeability, linked to the disassembly of tight junctions, which characterizes the initial phase of CD [48].

\section{Interesting is the following scheme}

Figure 3: It shows probiotic action's mechanism in the control of gastrointestinal symptoms in celiac patients

The figure shows probiotic action's mechanism in the control of gastrointestinal symptoms in celiac patients (Figure 3). Recent studies have shown that celiac subjects have an altered GM (1) and those with the HLA-DQ-2 or DQ-8 histocompatibility complex are predisposed to a state of dysbiosis (2). Celiac patients usually have gastrointestinal symptoms (3) that can persist also with a strictly GFD; moreover, the GM alteration can be one of the main causes of the persistence of gastrointestinal symptoms (4). Therefore, celiac patients mustfollow a GFD and reduce the intake of polysaccharides (fructans). These have a prebiotic action, and constitute one of the main sources of energy for the commensal bacteria of GM. This could further worsen intestinal dysbiosis (6). In turn, this leads to the persistence of gastrointestinal symptoms. To conclude this brief description on the correlation between GM and CD it's clear that the intestinal microbiota is an essential mediator of health. Its imbalance could be followed by an alteration of the functions of the microbiota with a negative impact on health. Research over the past ten years have shed new light on the role of the GM in $\mathrm{CD}$ and on the complex relationship between its composition, genetic background, GFD and persistence of clinical symptoms. 
Although many critical issues remain to be defined, some aspects are not yet clear. GM participates and mediates gluten-related inflammation. At present there is no defined CD microbial cluster, although some microbial alterations are consistently reported, both in biopsies and fecal samples (Bacteroides spp's abundance and Bifidobacterium spp's figure 3).

Some alterations in GM composition return to normal, while others are supported by a GFD and may be partly responsible for the persistence of symptoms in these patients. Some probiotics with proven clinical efficacy may be clinically helpful in controlling gluten-mediated inflammation and improving symptoms. It's the author's opinion that we future nutritionists have a key and important role in curing multiple diseases through diet. Informing and educating the patient is one of our most important challenges. The trend of the moment is to eat gluten-free products, moreover many people, without properly documenting themselves, claim that gluten is harmful to health. Why is it suggested to administer gluten-free products, even to non-celiac subjects? Because we don't know enough about food technology. In a gluten-free food there are well-defined structures that are added precisely because gluten is missing (gluten in the dough has an important structuring). Reading the labels of a gluten-free food we can notice that the caloric income is higher than that of a food containing gluten [49] In addition, these lipid matrices could have a negative effect on Bifidobacterium (remember that this bacterial species is a healthy marker).

Today, in gluten-free food products, we try to increase the fiber content precisely to mediate the negative effects of these structuring agents. In a person not suffering from $C D$, why should we trigger a dysbiosis, which over time could cause other negative effects? For this reason, gastroenterologists have risen up out against this trend, which is considered harmful and reckless for the health of the general population. This imprudence is precisely linked to dysbiosis, in celiac subjects, is mediated precisely by gluten free foods and by present structuring agents, which favor some species of the microbiota and, on the other hand, can limit others. This imprudence is precisely linked to the fact that dysbiosis, in celiac patients, is due to gluten-free foods and by the structures present, which favor some species of the microbiota and on the other hand, may limit other ones. It's the author's opinion that further studies are needed to understand all aspects of the GM and consequently to be able to implement new therapeutic approaches to various pathologies.

\section{References}

1. Oxentenko AS, Rubio Tapia A (2019) Celiac Disease. Mayo Clinic Proceedings 94(12): 2556-2571.

2. Kaplan GG, Ng SC (2017) Understanding and Preventing the Global Increase of Inflammatory Bowel Disease. Gastroenterology 152(2): 313-321.

3. Fasano A (2003) Prevalence of Celiac disease in at-risk and not-at-risk groups in the United States: A large multicenter study. Arch Intern Med 163(3): 286-292.

4. Hovell CJ (2001) High prevalence of coeliac disease in a populationbased study from Western Australia: A case for screening? Med J Aust 175(5): 247-250.

5. Parra-Medina (2015) Prevalence of celiac disease in Latin America: A systematic review and meta-regression. PLoS ONE.

6. Makharia GK, Catassi C (2019) Celiac Disease in Asia. Gastroenterology Clinics of North America 48: 1.

7. Singh P, Arora S, Singh A, Strand YA, Makharia GK (2016) Prevalence of celiac disease in Asia: A systematic review and meta-analysis. J Gastroenterol Hepatol 31(6): 1095-101.

8. Gatti S (2020) Increased Prevalence of Celiac Disease in School-age Children in Italy. Clin Gastroenterol Hepatol 18(3): 596-603.

9. Al-Bawardy B, Codipilly DC, Rubio Tapia A, Bruining DH, Hansel SL, et al. (2017) Celiac disease: a clinical review. Abdom Radiol 42(2): 351 360 .

10. Bul V, Sleesman B, Boulay B (2016) Celiac disease presenting as profound diarrhea and weight loss. A celiac crisis. Am J Case Rep 17: 559-561.

11. Jelsness-Jørgensen LP, Bernklev T, Lundin KEA (2018) Fatigue as an extra-intestinal manifestation of celiac disease: A systematic review. Nutrients 10(11): 1652

12. Ameghino L, Farez M, Wilken M, Goicochea M (2019) Headache in Patients with Celiac Disease and Its Response to the Gluten-Free Diet. J Oral Facial Pain Headache 33(3): 294-300.

13. Assiri AMA (2010) Isolated short stature as a presentation of celiac disease in Saudi children. Pediatr Rep 2(1): e4.

14. Rujner J, Metera M, Grajkowska W (1990) Delayed puberty in an 18-year-old female patient with late diagnosis of celiac disease. Pol Tyg Lek 45(38-39): 790-791.

15. Ganji R, Moghbeli M, Sadeghi R, Bayat G, Ganji A (2019) Prevalence of osteoporosis and osteopenia in men and premenopausal women with celiac disease: A systematic review. Nutrition Journal.

16. Casella G (2016) Celiac disease and obstetrical-gynecological contribution, Gastroenterology and Hepatology from Bed to Bench 9(4): 241-249.

17. Volta U, Caio G, Stanghellini V, De Giorgio R (2014) The changing clinical profile of celiac disease: A 15-year experience (1998-2012) in an Italian referral center. BMC Gastroenterol 14: 194.

18. Macho VMP, Coelho AS, Veloso e Silva DM, de Andrade DJC (2017) Oral Manifestations in Pediatric Patients with Coeliac Disease - A Review Article. Open Dent J 11: 539-545.

19. Izabela-Taiatella-Siqueira-Alves C, Fraiz FC, Celli A, Amenabar JM, Luciana-Reichert-Da-Silva A (2018) Dental and oral manifestations of celiac disease. Med Oral Patol Oral y Cir Bucal 23(6): e639-e645.

20. Rashid M, Zarkadas M, Anca A, Limeback H (2011) Oral manifestations of celiac disease: A clinical guide for dentists. J Can Dent Assoc (Tor) 77: b39.

21. Itzlinger A, Branchi F, Elli L, Schumann M (2018) Gluten-free diet in celiac disease-forever and for all? Nutrients 10(11): 1796.

22. Marušić M (2011) Celiac disease and fulminant T lymphoma detected too late in a 35-year-old female patient: Case report, Bosn. J Basic Med Sci 11(3): 190-193. 
23. Badyal RK, Sachdeva MUS, Varma N, Thapa BR (2014) A rare association of celiac disease and aplastic anemia: Case report of a child and review of literature. Pediatr Dev Pathol 17(6): 470-473.

24. Dimberg PL (2007) Fatal encephalitis in a patient with refractory celiac disease presenting with myorhythmia and carpal spasm. Mov Disord 22(3): 407-411.

25. Keller CE (2006) Fatal CNS vasculopathy in a patient with refractory celiac disease and lymph node cavitation. Virchows Arch 448(2): 209 213

26. Associazione Italia Celiachia sito internet.

27. Caio G (2019) Celiac disease: A comprehensive current review. BMC Medicine pp. 142.

28. Lionetti E, Castellaneta S, Francavilla R, Pulvirenti A, Catassi C (2017) Mode of Delivery and Risk of Celiac Disease: Risk of Celiac Disease and Age at Gluten Introduction Cohort Study. J Pediatr 184: 81.e2-86.e2.

29. Vriezinga SL (2014) Randomized feeding intervention in infants at high risk for celiac disease. N Engl J Med 371: 1304-1315.

30. Valitutti F, Cucchiara S, Fasano A (2019) Celiac disease and the microbiome. Nutrients 11(10): 2403.

31. Marasco G (2016) Gut Microbiota and Celiac Disease. Digestive Diseases and Sciences 61: 1461-1472.

32. Collado MC, Donat E, Ribes Koninckx C, Calabuig M, Sanz Y (2009) Specific duodenal and faecal bacterial groups associated with paediatric coeliac disease. J Clin Pathol 62(3): 264-269.

33. Nadal I, Donant E, Ribes Koninckx C, Calabuig M, Sanz Y (2007) Imbalance in the composition of the duodenal microbiota of children with coeliac disease. J Med Microbiol 56(Pt 12): 1669-1674.

34. Sánchez E, Donat E, Ribes Koninckx C, Calabuig M, Sanz Y (2010) Intestinal Bacteroides species associated with coeliac disease. J Clin Pathol 63: 12

35. Sánchez E, Donat E, Ribes Koninckx C, Fernández Murga ML, Sanz Y (2013) Duodenal-mucosal bacteria associated with celiac disease in children. Appl Environ Microbiol.

36. Ozuna CV, Iehisa JCM, Giménez MJ, Alvarez JB, Sousa C, et al. (2015) Diversification of the celiac disease $\alpha$-gliadin complex in wheat: $A$ 33-mer peptide with six overlapping epitopes, evolved following polyploidization. Plant J 82(5): 794-805.
37. Chibbar R, Dieleman LA (2019) The gut microbiota in celiac disease and probiotics. Nutrients.

38. Wacklin P (2014) Altered Duodenal microbiota composition in celiac disease patients suffering from persistent symptoms on a long-term gluten-free diet. Am J Gastroenterol 109(12): 1933-1941.

39. Krishnareddy S (2019) The Microbiome in Celiac Disease. Gastroenterology Clinics of North America 48(1): 115-126.

40. Losurdo G, Principi M, Iannone A, Ierardi E, Di Leo A (2016) The Interaction between Celiac Disease and Intestinal Microbiota. J Clin Gastroenterol 2015: S145-S147.

41. Cristofori F, Indrio F, Miniello FL, De Angelis E, Francavilla R (2018) Probiotics in celiac disease. Nutrients 10(12): 1824.

42. Plaza Diaz J, Ruiz Ojeda FJ, Gil Campos M, Gil A (2019) Mechanisms of Action of Probiotics. 10(suppl1): S49-S66.

43. La Fata G, Weber P, Mohajeri MH (2018) Probiotics and the Gut Immune System: Indirect Regulation. Probiotics and Antimicrobial Proteins 10(1): 11-21.

44. Olivares M, Laparra M, Sanz Y (2011) Influence of bifidobacterium longum CECT 7347 and gliadin peptides on intestinal epithelial cell proteome 14: 7666-7671.

45. Medina M, De Palma G, Ribes Koninckx C, Calabuig M, Sanz Y (2008) Bifidobacterium strains suppress in vitro the pro-inflammatory milieu triggered by the large intestinal microbiota of coeliac patients. J Inflamm pp. 1476-9255.

46. De Angelis M (2006) VSL\#3 probiotic preparation has the capacity to hydrolyze gliadin polypeptides responsible for Celiac Sprue. Biochim Biophys. Acta- Mol Basis Dis 1762(1): 80-93.

47. Wang W, Uzzau S, Goldblum SE, Fasano A (2000) Human zonulin, a potential modulator of intestinal tight junctions. J Cell Sci 113: 44354440 .

48. Fasano A, Zonulin (2000) A newly discovered modulator of intestinal permeability, and its expression in coeliac disease. Lancet 355(9214): 1518-1519.

49. Dalia El Khoury, Skye Balfour-Ducharme, Iris J Joye (2018) A Review on the Gluten-Free Diet: Technological and Nutritional Challenges Nutrients 10(10): 1410 .

\section{Your next submission with JuniperPublishers} will reach you the below assets

- Quality Editorial service

- Swift Peer Review

- Reprints availability

- E-prints Service

- Manuscript Podcast for convenient understanding

- Global attainment for your research

- Manuscript accessibility in different formats

( Pdf, E-pub, Full Text, audio)

- Unceasing customer service

Track the below URL for one-step submission https://juniperpublishers.com/online-submission.php 